but it is surely observed that staining reactions coincide with the biochemical results of cellular fractions.

(To Dr. Ogawa) We showed the lineal staining of brush border like Essmer-Novikoff's findings.

\title{
Histochemical Studies on Copper Metabolism
}

\author{
Shigeo OKinaka, Masaki Yoshikawa, Toshiji MozaI, \\ Haruo Watanabe, Toshio Terao, Kazuaki Ogiwara \\ and Shunsaku HiraI.
}

The Third Department of Internal Medicine (Director: Prof. S. Okinaka, M. D.), Faculty of Medicine, University of Tokyo.

The mechanism of deposition of copper in the tissue of patients with hepatolenticular degeneration (HLD) is not fully understood.

We studied on copper metabolism in intra-uterine life, in patients with HLD as well as ordinary acquired liver diseases, and in experimental copper intoxication in relation to the pathogenesis of HLD.

\section{Material and Methods}

\section{Materials}

1. Copper and ceruloplasmin concentrations in the serum obtained from the patients with HLD, other acquired liver diseases and from the cubital vein and umbilical cord of normal healthy pregnant women at the time of delivery were estimated.

2. The livers of 8 cases of HLD, of 24 cases of other acquired liver diseases, and of 19 cases of fetuses, all fixed in $10^{\circ}$ neutralized formalin solution for quantitative and or histochemical analysis for copper.

3. The livers of copper intoxicated adult dogs were analysed for copper biochemically as well as histochemically.

Methods

Serum ceruloplasmin concentration was determined using Ravin's method ${ }^{12}$. Copper content in serum and tissue were determined using the method previously reported ${ }^{2}$. Histochemical demonstration for copper was performed according to Okamoto and Utamura ${ }^{8)}$. In addition, the livers of HLD were studied using the method of Fredericq and Schevremont" for the demonstration of reducing radical of protein.

\section{Results}

In our study, following points were demonstrated.

1. The concentration of serum ceruloplasmin in the blood from umbilical 
cord was far less than normal, whereas that of the pregnanted women was much higher than the normal.

2. The copper content in the liver of fetus was larger than the adult, and was found in most high concentration in the age of five to six month. Histochemical staining for copper in these fetus livers showed deposition of copper in the cytoplasma of cells around the vessels.

3. In the livers of acquired liver diseases other than HLD was found sometimes slight increase in copper content. Histochemical demonstration for copper in these livers revealed that the Kupffer cells played a large part of role in deposition of copper.

4. In experimental copper intoxication in the dogs, the deposited copper in the liver was demonstrated in several cells, presumably in Kupffer cells, in some lobules, when the increase in the content of copper remained minimal. When the content of copper exceeded more than $30 \mathrm{mg} / 100 \mathrm{gr}$ of tissue in dry weight the deposited copper was demonsted uniformly throughout the entire liver.

5. In the liver of HLD, histochemical demonstration for copper revealed an irregular and insular pattern of distribution. Pseudolobules composed of liver cells filled with copper granules were seen scattering among the many pseudolobules composed of copper negative liver cells.

6. Histochemical demonstration for reducing activity according to Shevremont and Fredericq's method in the liver of HLD showed the preservation of reducing activity from the destruction caused by the long fixation of preparation in $10^{\circ}$ o neutralized formol solution for more than one month. Moreover, it was found that the reducing activity was not closed by immersion the preparation in saturated solution of mercury chloride.

\section{Comment}

Our study on copper metabolism during intra-uterine life supported the general view that the accumulation of copper in the liver tissue of HLD was due to the characteristic alteration in blood chemistry (low ceruloplasmin concentration and accompanied relatively high non-ceruloplasmin copper concentration in serum), which was also found in the umbilical cord blood.

On the other hand, marked difference in histochemical findigs between HLD and experimental copper intoxication was demonstrated. This fact indicate the existence of some mechanism in the liver cell to precipitate copper in HLD in addition to the alteration in blood.

From the histochemical study, demonstrated the binding of copper to reducing radical of protein, we suggest the existence of abnormal protein, which has high affinity to copper, in the liver cell in HLD.

\section{References}

1) Ravin H. A. : Lancet 726, $1956 . \quad$ 2) Mozai T.: Nisshin Igaku $39: 273,1953 . \quad 3$ ) Okamoto K. and Utamura M. : Acta Scholae med. Kyoto $20: 573,1938.4$ 4) Lison L.: Histochimie et cytochimie animales, 1953. 